\title{
Educação especial no município de São Paulo: acompanhamento DA TRAJETÓRIA ESCOLAR DE ALUNOS NO ENSINO REGULAR ${ }^{1}$ SPECIAL EDUCATION IN THE CITY OF SÃo PAULO: FOLLOWING STUDENTS' SCHOLASTIC YEARLY PROGRESSION IN REGULAR CLASSES
}

\author{
Rosângela Gavioli PRIETO² \\ Sandra Zákia Lian SOUSA ${ }^{3}$
}

\begin{abstract}
RESUMO: o artigo apresenta resultados de pesquisa acerca da política de atendimento aos alunos com necessidades educacionais especiais da rede municipal de ensino de São Paulo, implementada a partir de 1993. Focaliza as ações direcionadas ao portador de deficiência mental, por meio das Salas de Atendimento aos Portadores de Necessidades Especiais (SAPNE). Tendo como propósito analisar eventuais contribuições desse atendimento para a integração escolar dos alunos, procedeu-se à caracterização das trajetórias escolares daqueles que freqüentavam as SAPNE no decorrer do segundo semestre de 1997 até 2001. As evidências acerca dessa trajetória escolar indicaram, dentre outras constatações, que a SAPNE nem sempre tem sido um recurso suficiente para viabilizar o atendimento integrado de parcela de alunos com deficiência mental na classe comum e a necessidade de maior investimento na garantia de condições políticas, técnicas e materiais para sua implementação.
\end{abstract}

PALAVRAS-CHAVE: política educacional; educação especial; integração escolar.

\begin{abstract}
: this article presents research results on service delivery to students with special needs in the municipal school system of São Paulo implemented as of 1993. It focuses on actions planned assist students with mental deficiency through the Classroom Service for Students with Special Needs (Salas de Atendimento aos Portadores de Necessidades Especiais (SAPNE)). In order to analyze possible contributions of this kind of service to school integration of these students, we proceeded to carry out a characterization of the yearly progression of those who attended the SAPNE program from the second semester of 1997 through 2001. Among other findings, the evidence showed that SAPNE isn't as efficient a resource as it should be, enabling integrated attendance in regular classrooms for that portion of students who present mental deficiency. What is needed to implement the service and make it effective is a greater investment of public funding, technical support and material conditions.
\end{abstract}

KEYWORDS: educational policy; special education; school integration.

\section{INTRODUÇÃO}

Privilegiando o atendimento de alunos com necessidades educacionais especiais em classes comuns, a Secretaria Municipal de Educação de São Paulo (SME-SP) implantou, a partir de 1993, as Salas de Atendimento aos Portadores de Necessidades Especiais (SAPNE). ${ }^{4}$

\footnotetext{
${ }^{1}$ Financiamento na modalidade iniciação científica - CNPq e FAPESP.

${ }^{2}$ Doutora, docente da Faculdade de Educação da USP - rosangel@usp.br

${ }^{3}$ Doutora, docente da Faculdade de Educação da USP - sanzakia@usp.br

${ }^{4}$ Em 18 de outubro de 2004, pelo Decreto n. ${ }^{\circ} 45.415$, que "Estabelece diretrizes para a Política de Atendimento a Crianças, Adolescentes, Jovens e Adultos com Necessidades Educacionais Especiais no Sistema Municipal de Ensino", essas salas passaram a ser denominadas como Salas de Apoio e Acompanhamento à Inclusão (SAAI).
} 
Com o propósito de analisar as potencialidades das SAPNE para alunos com deficiência mental se constituírem em um recurso especial de atendimento integrado à escola regular, realizou-se a pesquisa ora relatada sobre as trajetórias escolares dos que freqüentavam essas salas, identificando-se características e tendências dessas trajetórias, num período de cinco anos de escolarização.

Dispúnhamos de informações sobre a situação escolar de 505 alunos que freqüentavam a SAPNE em 1997, ano em que as autoras deste texto realizaram estudo avaliativo sobre as condições de implantação e funcionamento das salas organizadas para atendimento de alunos deficientes mentais ${ }^{5}$. Assim, no ano de 2001, desenvolvemos a pesquisa, objeto do presente texto, focalizando o percurso desses alunos, no decorrer desses anos.

As indagações que orientaram seu desenvolvimento foram: Os alunos daquela época continuavam no ensino regular? Se sim, em que ano se encontravam? Se não, onde estavam em 2001? Estavam sendo atendidos por meio de outro recurso de educação especial? Abandonaram a escola? A freqüência a SAPNE contribuiu para a permanência desses alunos no ensino regular? A freqüência a SAPNE possibilitou a parcela desses alunos autonomia para continuar no ensino regular, sem acompanhamento paralelo? Os alunos apresentaram desempenho satisfatório no decorrer de sua trajetória escolar no ensino regular, tomando-se como referência os conceitos atribuídos pelos professores, nas diferentes disciplinas?

O que se buscou com a pesquisa, cujos resultados são aqui apresentados de modo sucinto, foi identificar evidências que possibilitem inferir como vem se concretizando o princípio da inclusão escolar de alunos com deficiência mental na rede municipal de ensino, trazendo subsídios para análise da formulação e implementação de políticas públicas da área.

Ainda que o atendimento educacional de alunos com deficiência mental preferencialmente deva se dar na rede regular de ensino (cf. art. 208, inciso III, $\mathrm{CF} / 88)^{6}$, atender a esse objetivo não é meramente viabilizar seu acesso ao ensino regular. É também garantir sua permanência na escola, com condições de ensino que, de fato, respondam às suas necessidades educacionais específicas.

Portanto, a inclusão dos alunos deficientes mentais na escola regular só se realiza, de fato, se houver respeito à diferença, evidenciado pela interação com as possibilidades e limitações desse alunado, por meio de práticas pedagógicas que estimulem o seu desenvolvimento.

Porém, antes de apresentar e discutir os dados que respondem as mencionadas indagações, serão registradas, brevemente, informações que caracterizam o funcionamento dessas salas de atendimento educacional

\footnotetext{
${ }^{5}$ SOUSA, S. M. Z. L. e PRIETO, R. G. Política de atendimento aos alunos com necessidades educacionais especiais da rede municipal de ensino de São Paulo, implementada a partir de 1993: análise das ações direcionadas ao portador de deficiência mental. São Paulo/FEUSP, Relatório de Pesquisa, 2000 (Mimeo).

${ }^{6}$ Constituição Federal de 1988, doravante denominada CF/88.
} 
especializado e mencionados argumentos que têm estado presentes nas manifestações de movimentos nacionais e internacionais, direta ou indiretamente, voltados à defesa do direito à educação dos alunos com deficiência.

\section{Recursos educacionais especiais: ALGUNS DAdOS SObRe As SAPNE}

A Secretaria Municipal de Educação de São Paulo, a partir de 1993, pelo Decreto n. ${ }^{\circ} 33.891$, previa que o atendimento educacional aos alunos com necessidades educacionais especiais deve ser garantido preferencialmente na rede regular de ensino em SAPNE.

Essas salas podiam funcionar como "atendimento paralelo", em que o aluno era regularmente matriculado em classe do ensino comum e recebia apoio educacional complementar ou suplementar em horário diverso, ou "atendimento exclusivo", freqüentando somente a SAPNE.

Além dessas modalidades, estava prevista, no referido Decreto, a possibilidade de atendimento em instituições especializadas, portanto também exclusivo, dos alunos cuja avaliação comprovasse que não podiam se beneficiar da SAPNE. Nesse caso, deveriam ser "encaminhados para as vagas disponíveis oferecidas pelas entidades sem fins lucrativos, que mantenham convênio com a Secretaria Municipal de Educação" (SÃO PAULO, Decreto n. ${ }^{\circ}$ 33.891, art. $7^{\circ}$ ).

Na política de educação do município de São Paulo, sob o aspecto educacional, eram considerados como portadores de necessidades especiais:

\footnotetext{
[...] os alunos que apresentem desvio da média considerada normal para uma faixa etária nos aspectos físicos, sensorial, mental por deficiência ou superdotação, e que necessitem de recursos educativos especiais, para o pleno desenvolvimento de suas potencialidades e integração no meio social. (SÃO PAULO, Decreto n. ${ }^{\circ} 33.891$, art. $3^{\circ}$ )
}

Especificando essa definição, o atendimento educacional, por meio das SAPNE, era previsto para alunos com "distúrbios das capacidades básica de aprendizagem" e com "deficiência mental leve", população ao qual se dirigiu esta pesquisa, para os "surdos" e os com "deficiência auditiva", para os que apresentem "deficiência física", com 'alterações ortopédicas e/ou neurológicas", os "cegos" e com "deficiência visual" e para os "superdotados" ou com "altas habilidades' (SÃO PAULO, Decreto n. ${ }^{\circ} 33.891$, art. $5^{\circ}$ ).

\section{EDUCAÇÃO PARA TODOS: RECOMENDAÇÕES BRASILEIRAS E INTERNACIONAIS}

No Brasil, ações em favor da integração escolar dos alunos com deficiência vêm se concretizando há anos e, historicamente, têm sido influenciadas pelos movimentos internacionais, direta ou indiretamente, voltados à defesa de seu direito à educação. 
Do ponto de vista filosófico, a educação especial fundamenta-se na "Declaração Universal dos Direitos do Homem" 7 e na "Convenção sobre os Direitos da Criança" 8 , que visam a promover o respeito universal aos direitos e liberdades fundamentais do homem e, entre esses, "a educação para todos, indistinta ou independentemente de suas origens ou condições sociais" (BRASIL, Série Diretrizes; 7, 1995, p. 7).

Dentre as diretrizes e recomendações internacionais, tem sido referência importante para constituição da agenda brasileira, a partir da década de 90, as emanadas da "Conferência Mundial de Educação para Todos", realizada em Jomtien, na Tailândia, em março de 1990 (UNICEF, 1991).

O documento síntese dessa conferência, intitulado “Declaração Mundial sobre Educação para Todos e o Plano de Ação para Satisfazer as Necessidades Básicas de Aprendizagem", além de representar "um consenso Mundial sobre uma visão abrangente de educação básica", contém recomendações e diretrizes gerais com vistas a impulsionar os países a assumirem o compromisso político de garantir educação para todos ou, na falta de condições para tal, universalizar o ensino fundamental, pelo menos (UNICEF, 1991).

Em decorrência das deliberações da referida reunião internacional, em junho de 1994, realizou-se em Salamanca, na Espanha, a "Conferência Mundial sobre Necessidades Educativas Especiais: acesso e qualidade", que aprovou os documentos "Declaração de Salamanca e Linha de Ação sobre Necessidades Educativas Especiais" (BRASIL, Declaração de Salamanca, 1997).

Nesses documentos são encontradas recomendações e orientações para que Organizações Governamentais (OG) e Organizações Não Governamentais (ONG) possam garantir educação para todos, considerando como princípio norteador que essa deva se dar pela escola comum.

Todavia, ainda que na Declaração de Salamanca (1994) seja proposto o atendimento de todos em escolas integradoras ${ }^{9}$, não se desconsidera a manutenção e/ou ampliação de recursos educacionais especiais, tal como pode ser constatado em suas orientações:

8. Nas escolas integradoras, as crianças com necessidades educativas especiais devem receber todo apoio adicional necessário para garantir uma educação eficaz. A escolarização integradora é um meio mais eficaz para fomentar a solidariedade entre as crianças com necessidades especiais e seus colegas. A escolarização de crianças em escolas especiais - ou classes especiais na escola de caráter permanente - deveria ser uma exceção, só recomendável naqueles casos, pouco freqüentes, nos quais se demonstre que a educação nas classes comuns não

\footnotetext{
${ }_{7}$ Também denominada Declaração Universal dos Direitos Humanos, foi proclamada no dia 10 de dezembro de 1948, pela Organização das Nações Unidas (ONU).

${ }^{8}$ Realizada pela UNESCO, em 1989.

9 "O desafio que enfrentam as escolas integradoras é o de desenvolver uma pedagogia centrada na criança, capaz de educar com sucesso todos os meninos e meninas, inclusive os que sofrem de deficiências graves" (BRASIL, Declaração de Salamanca, 1994, p. 18).
} 
pode satisfazer às necessidades educativas ou sociais da criança, ou quando é necessário para o bem-estar da criança ou de outras crianças. (BRASIL, Declaração de Salamanca, 1997, p. 23, grifo nosso)

Ressalte-se que, no Brasil, é dever legal e político do poder público garantir que os alunos que ingressam nas escolas regulares dela não sejam expulsos e tenham as condições necessárias para atingir a terminalidade dos estudos e isso depende de investimentos na qualidade da educação, pois é no ensino regular que esses alunos deveriam passar a maior parte do tempo e é onde deveriam ter assegurado o acesso ao conhecimento e condições para atingir ao máximo suas possibilidades de desenvolvimento e aprendizagem.

Uma das alternativas que podem trazer contribuições para a melhoria da qualidade do ensino oferecido aos alunos com deficiência é a realização de estudos que analisem e avaliem as políticas públicas de atendimento educacional especializado. É nessa perspectiva que se insere a pesquisa desenvolvida acerca da trajetória escolar de alunos com deficiência mental atendidos nas SAPNE. ${ }^{10}$

Na rede municipal de ensino de São Paulo, essas salas se constituíam até 2004, como já mencionado, a única alternativa de atendimento educacional especializado oferecida em escolas regulares aos alunos com deficiência mental. ${ }^{11}$ Portanto, a investigação sobre seus efeitos no sentido de garantir seu acesso e permanência na classe comum significa analisar e avaliar resultados das ações públicas em educação especial no município de São Paulo.

\section{O DESENVOLVIMENTO DA PESQUISA}

Foram resgatados dados dos alunos que eram atendidos pelas SAPNE de 1997 a 2001, por meio de entrevista com as professoras dessas salas, que estavam atuando em 2001, consultando-se os registros disponíveis com as professoras bem como prontuários arquivados nas escolas. Ainda, quando necessário, recorreu-se a diretores e coordenadores pedagógicos das escolas, visando a complementação de informações.

Sobre a trajetória escolar dos alunos, procurou-se identificar quantos e quais permaneceram na mesma escola ou foram para outras escolas e, nesse caso, se essas eram regulares ou especiais, ou que estavam sem atendimento escolar, desde quando e por quais motivos, bem como qual o desempenho escolar deles no período de 1997 a 2001.

\footnotetext{
${ }^{10}$ Doravante denominadas SAPNE-DM.

${ }^{11}$ Esta afirmação tem como referência o período de 1993 a 2004, pois segundo o novo decreto, as SAPNEs passam a ser denominadas Salas de Apoio e Acompanhamento à Inclusão (SAAIs) e além dessas, "Considerase serviços de Educação Especial aqueles prestados em conjunto, ou não, pelo Centro de Formação e Acompanhamento à Inclusão - CEFAI, pelo Professor de Apoio e Acompanhamento à Inclusão - PAAI, ora criados [...]".
} 


\section{O universo pesquisado}

Em 1997, ano em que, como já mencionado, foi desenvolvida a outra pesquisa cujos dados serviram de base para esta, foram visitadas 20 escolas e entrevistadas 21 professoras que atuavam em 22 SAPNE, pois uma professora assumia duas salas em uma mesma escola. Desse universo, em 2001, foram resgatadas informações sobre os alunos de 15 dessas salas, que funcionavam em 14 escolas. A diminuição no número de salas deveu-se ao fato de que, de 1997 a 2001, quatro terem sido desativadas e, também, por não ter sido possível realizar as entrevistas com as professoras de três salas.

Das três docentes não entrevistadas, duas declararam não ter os dados de 1997 porque as professoras daquela época não deixaram registros sobre os alunos; a outra, alegando acúmulo de atividades, se dispôs a agendar a visita apenas para o início do ano seguinte, o que seria inviável frente ao cronograma da pesquisa.

Constatou-se que 11 das 17 professoras atuantes em 2001 eram as mesmas de 1997, havendo, portanto, seis novas docentes em atividade nas SAPNE, das quais três não se conseguiu entrevistar.

\section{Abrangência das informações obtidas}

Dos 505 alunos que freqüentavam a SAPNE em 1997, foram resgatadas informações de 310 destes. A não obtenção da totalidade das informações previstas deveu-se aos seguintes fatores:

- não havia uma sistemática adotada pela Secretaria Municipal de Educação de São Paulo de acompanhamento do atendimento em SAPNE, ou mesmo uma orientação comum às escolas para registro e arquivo da documentação relativa à trajetória dos alunos atendidos, ficando a cargo das escolas ou somente de sua professora qualquer iniciativa de organização de informações;

- as escolas, por sua vez, não tinham a prática de implantar uma sistemática especial para registro da trajetória escolar dos alunos que freqüentam SAPNE, pois seus registros escolares não incluíam os eventuais atendimentos paralelos ao ensino comum; mesmo os alunos que freqüentam exclusivamente as SAPNE não contavam com documentação específica na secretaria das escolas.

Essas constatações evidenciam, portanto, a ausência de uma fonte de consulta "oficial" sobre dados da trajetória escolar desses alunos, com o registro de sua movimentação entre sala comum e SAPNE. As informações existentes eram as organizadas pela professora regente da sala, que o fazia por iniciativa própria. Daí resulta uma diversidade nos dados disponíveis, que variam quanto à forma de registro, grau de detalhamento e de conteúdo.

Essa iniciativa das professoras foi de grande valor, constituindo-se na única fonte disponível para um conhecimento mais acurado da trajetória dos alunos que freqüentavam SAPNE. Há que se registrar que elas mantinham "preciosos 
cadernos" com informações não só dos alunos que estavam em atendimento, mas também dos freqüentes em anos anteriores. Todavia, usando esse procedimento, quando essas professoras deixavam a escola também se perdia a história dos alunos e do trabalho realizado em SAPNE.

Assim, a inexistência de uma sistemática de acompanhamento e registro da trajetória escolar dos alunos explica a não obtenção de informações de 195 alunos. Ou seja, em 1997:

- 108 alunos freqüentavam salas que, em 2001, estavam desativadas, não havendo registro, na escola, sobre sua trajetória escolar, seja no ensino comum e/ ou no especial;

- $\quad 48$ alunos freqüentavam salas em que houve mudança das professoras; assim as professoras responsáveis pelas salas em 2001 não dispunham de dados sobre os antigos alunos, pois esses se foram com a saída das antigas professoras;

- uma das salas que tinha 31 alunos estava, em 2001, sob responsabilidade de uma nova professora, que informou não disponibilidade para prestar informações, alegando acúmulo de trabalho; no entanto, tal como ocorreu com as professoras mencionadas no item anterior, supõe-se que essa possivelmente encontrasse dificuldade em fornecer as informações necessárias, pois não era a responsável pela sala naquele ano.

Ainda, a não obtenção de informações sobre oito alunos possivelmente decorre da diferença entre o número de alunos declarado pelas professoras em atendimento nas SAPNE em $1997^{12}$ e o registro da professora, consultado em 2001, sobre aqueles alunos.

Como se pode observar, caso houvesse maior mobilidade de professores em SAPNE provavelmente não teria sido possível a realização da presente pesquisa. Além das indicações já apresentadas que sustentam essa suposição, registra-se também que foram mais completas e precisas as informações obtidas sobre os alunos quando não houve mudança do professor responsável pela sala.

\section{Características dos alunos}

Na investigação, tal como mencionado, foram resgatados os dados de 310 alunos das SAPNE-DM, assim como sua trajetória escolar até o ano de 2001. A análise desses dados apontou que no ano de 1997, desse total de alunos, 204 eram meninos $(65,8 \%)$ e 106 meninas $(34,19 \%)$. No ano de 2001, 68 alunos continuavam na SAPNE, sendo 44 meninos (64\%) e 24, meninas (35,2\%), reproduzindo, portanto, o quadro encontrado em 1997, cuja maioria era masculina.

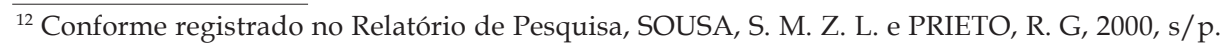


Essa evidência reitera a suposição levantada na primeira pesquisa de que o motivo do encaminhamento dos alunos para a SAPNE podia estar sendo baseado em outros critérios que não a deficiência mental, já que o pressuposto de que os meninos apresentem, em maior número, tal deficiência é descartado. $\mathrm{O}$ dado, portanto, torna a sugerir que os meninos, mais que as meninas, por apresentarem comportamentos tidos como não adequados aos padrões escolares, venham a ser, com maior freqüência, encaminhados a SAPNE, sem que apresentem algum tipo de deficiência mental.

Ainda em relação às características dos alunos, pode-se verificar que apesar de a SAPNE-DM estar atendendo, àquela época, alunos matriculados em diferentes níveis de ensino, inclusive na Educação de Jovens e Adultos (EJA), havia concentração de alunos com idade compatível ao alunado do ensino fundamental.

Assim sendo, 24 desses alunos possuíam entre 04 e 06 anos (7,7\%), idades correspondentes ao nível Pré-escolar; 29 deles tinham 15 anos ou mais $(9,35 \%)$, sendo, provavelmente, alunos matriculados em curso supletivo. Os alunos cuja idade correspondia ao ensino fundamental totalizaram 257 , ou seja, $82,9 \%$ do total, evidenciando, de modo dominante, uma tendência de serem atendidos em SAPNE os alunos matriculados nesse nível de ensino. Dentre esses 257 alunos, 150 deles tinham entre 07 e 10 anos, representando 66,7\% do total. Esse número permite inferir que a maior parte dos alunos atendidos pela SAPNE, no ano de 1997, se concentrava no primeiro ciclo do ensino fundamental.

\section{A trajetória escolar dos alunos}

São aqui retomadas as indagações que orientaram o levantamento dos dados, cujas respostas obtidas permitem, em seu conjunto, compreender a trajetória de alunos que freqüentavam a SAPNE em 1997. Os dados apresentados referemse aos 310 alunos dos quais se obteve informações, embora, nem sempre completas, pois muitas vezes as professoras alegaram desconhecimento de um ou mais aspectos a eles relacionados.

\section{Os alunos continuavam no ensino regular?}

Essa informação foi obtida para 195 alunos, pois as professoras desconheciam o destino de 115 dos 310 alunos após sua saída da SAPNE. No decorrer do período 1997/2001, seguiram sua trajetória escolar, freqüentando classe comum, 145 dos 195 alunos (74\%). Desses, 47 (32\%) contavam, em 2001, com algum apoio educacional paralelo à classe comum: 43 ainda com SAPNE e quatro com Sala de Apoio Pedagógico (SAP) ${ }^{13}$.

\footnotetext{
${ }^{13}$ As Salas de Apoio Pedagógico da rede municipal de ensino de São Paulo são destinadas ao atendimento de alunos que apresentem distúrbios de aprendizagem ou dificuldades de aprendizagem ou, ainda, distúrbios das capacidades básicas de aprendizagem (PRIETO, 2000, p. 206). Portanto, não deveriam, em tese, atender a alunos com deficiência, que são elegíveis para as SAPNEs.
} 
Em 2001, a situação escolar dos 50 alunos que não mais estavam freqüentando classe comum era a seguinte: 19 alunos estavam em classe especial de escolas da rede estadual; nove estavam em escola especial; cinco estavam realizando curso profissionalizante; cinco estavam sendo atendidos por instituições assistenciais; 12 estavam fora da escola, sendo que desses: cinco $^{14}$ freqüentavam exclusivamente a SAPNE, embora não estivessem matriculados na escola; sete abandonaram a escola e estavam sem qualquer tipo de atendimento, sendo que um destes alunos havia iniciado atividade profissional em 2001. Essas trajetórias nos alertam para o fato de que $26 \%$ dos alunos dos quais obtivemos informações não permaneceram no atendimento escolar integrado.

Que motivos levaram ao desligamento de alunos da SAPNE?

Quando se indagou às professoras sobre os motivos de saída do aluno da SAPNE, o que se esperava constatar, caso as SAPNE estivessem cumprindo seu papel de apoio à freqüência do aluno à classe comum, era o seu desligamento quando já não demandassem atendimento paralelo para que apresentassem um bom desempenho escolar. No entanto, além dessa, outras razões foram indicadas pelas professoras, ao comentarem que alguns alunos não estavam mais freqüentando as SAPNE, embora, em sua opinião, demandassem a continuidade desse atendimento.

Ao todo, obteve-se 273 manifestações das professoras sobre motivos de saída do aluno da SAPNE, sendo que algumas alegaram mais de um motivo de saída. Apenas 34 dessas manifestações $(12 \%)$ referiram-se a alunos que deixaram a SAPNE por apresentarem condições de acompanhar a classe comum, sem apoio paralelo, afirmando que esses estavam conseguindo "um bom desempenho escolar" ou que já haviam superado a dificuldade que apresentavam. O maior número de menções (34\%) recaiu em razões que se denominaram administrativas ou legais, a seguir indicadas: quando passam para a $5^{\text {a }}$ série os alunos são dispensados de SAPNE em decorrência do "excesso de demanda" ou por ser uma norma da escola; com uma só sala em funcionamento na escola, não era possível atender a todos os alunos de outras escolas que procuravam a SAPNE, mesmo sendo da rede municipal; o número reduzido de vagas disponíveis levava à necessidade de seleção dos alunos "mais comprometidos"; a lei restringia o atendimento a alunos de escolas municipais, assim foram dispensados os alunos não matriculados em escolas municipais ou os "sem escola"; o aluno com "idade avançada" não era atendido em SAPNE; o horário de atendimento em SAPNE era coincidente com o horário da classe comum; transferência do aluno para outra escola, não sendo possível dar continuidade ao atendimento, mesmo no caso de transferência para escola da rede municipal; dificuldade de transporte, sendo "distante a casa do aluno da escola";

\footnotetext{
${ }^{14}$ Uma destas alunas faleceu em 2000 e na ocasião já não estava matriculada na classe comum, só freqüentava a SAPNE.
} 
aluno "convidado" a sair da escola, deixando assim de freqüentar a SAPNE; a SAPNE deixou de funcionar porque a professora responsável saiu da escola.

Essas informações são evidências da precariedade da implantação desse atendimento, seja em relação ao seu dimensionamento frente à demanda, seja em relação à fragilidade de seus mecanismos de sustentação, o que pode ser exemplificado quando não se têm alternativas para substituição de uma professora que se afasta ou mesmo pela não existência de um serviço de apoio ao transporte dos alunos.

Também foram feitas várias referências aos alunos ou às suas mães, atribuindo-lhes, por necessidade ou por decisão, responsabilidade pela não continuidade do atendimento em SAPNE. As 76 manifestações referentes aos alunos expressaram, quase em sua totalidade, que esses "abandonaram", "desistiram", "saíram", "desapareceram" da SAPNE, como uma constatação, sem indicação do motivo, e quando havia sua explicitação o motivo alegado era a mudança de residência (de bairro, de cidade, de estado).

Quanto às mães, as falas das professoras revelaram de modo dominante, três tipos de motivações que as levaram a "desistir" do atendimento em SAPNE:

- não aceitação da deficiência do (a) filho (a), com depoimentos do tipo: "mãe impediu de continuar com o atendimento porque nega a deficiência da filha"; "mãe não o queria na SAPNE, pois não aceita a deficiência", "mãe considerou desnecessário o atendimento porque o aluno já estava alfabetizado";

- descrença quanto à possibilidade de contribuição da SAPNE para o desenvolvimento da criança, com referências do tipo: "a mãe avisou que ela não iria mais a SAPNE porque não ia mesmo aprender"; "a mãe optou pela sala especial do Estado"; "mãe não acreditou no trabalho da SAPNE";

- não possibilidade de trazer o (a) filho (a) para atendimento, afirmando que a "mãe desistiu do atendimento porque não tinha tempo para trazer a filha à escola" ou "a mãe teve bebê". Dentre as 17 referências feitas às mães, algumas consistiram apenas em uma afirmação de que a "mãe desistiu do atendimento".

O que se evidenciou nos depoimentos que fizeram menção aos alunos ou às suas mães é que parte deles não elucidava as motivações das decisões tomadas. No entanto, alguns nos alertaram para a necessidade do estabelecimento de relações mais próximas entre a escola e as famílias dos alunos, particularmente ações de formação direcionadas às mães, pois, usualmente, são elas que acompanham a interação do filho com a escola.

Além dos motivos mencionados pelas mães, com menor freqüência, os professores atribuíram a saída do aluno da SAPNE freqüentada em 1997: a transferência de escola, passando a freqüentar outra SAPNE; ao encaminhamento para atendimento especial em escola estadual, Associação de Pais e Amigos dos Excepcionais (APAE) ou oficina. Ainda, houve indicações da não adequação da 
SAPNE às necessidades apresentadas pelo aluno, com manifestações do tipo: "o aluno tinha muitas dificuldades e o ensino da SAPNE não fazia sentido", "não tinha condições de freqüentar a SAPNE", "o aluno não parava, mordia".

Essas últimas afirmações indicaram a necessidade de oferta de outros recursos especiais de educação no âmbito da rede municipal de ensino, visando a atender alunos que eventualmente demandem para seu desenvolvimento outras modalidades de auxílios ou serviços especiais ou, até mesmo, o funcionamento da SAPNE como atendimento exclusivo, o que era previsto na regulamentação vigente na rede municipal, mas não implantado nas escolas.

Que motivos levaram os alunos às SAPNE?

Quando se perguntou às professoras sobre os motivos de seus alunos terem sido encaminhados à SAPNE, não se obteve esclarecimento para 123 dos 310 alunos, ou seja, para $40 \%$ dos alunos não foi indicada pela professora a(s) causa(s) do seu encaminhamento. Esse fato merece registro porque era previsto na legislação em vigência à época que o encaminhamento de alunos para a SAPNE fosse precedido de diagnóstico médico ou psicológico, no caso de suspeita de deficiência mental (SÃO PAULO, Decreto nº. 33.981). Essa constatação reitera evidência já apontada na pesquisa realizada em 1997, quando se indicou que:

Embora todas as professoras demonstrassem conhecer a necessidade de uma
avaliação dos alunos, feita por profissional habilitado para o diagnóstico da
deficiência mental, em complementação ao diagnóstico educacional, feito pela
professora da classe em que o aluno estava matriculado, foram unânimes em
reconhecer que este procedimento dificilmente era seguido, pela excessiva
demora em se obter a avaliação, realizada por instituições conveniadas com a
Prefeitura Municipal. (SOUSA; PRIETO, 2000, mimeo)

As professoras que informaram as razões que levaram os alunos a ser encaminhados às SAPNE expressaram-se com diferentes graus de precisão, bem como, algumas delas, indicaram mais de uma causa, não destacando a causa principal. Ao que parece, a decisão de encaminhamento do aluno à SAPNE era apenas da escola, usualmente envolvendo a professora da classe comum e a da SAPNE, em que essas nem sempre dispunham, mesmo quando necessário, de subsídios de laudos psicológico ou médico que apoiassem tal encaminhamento.

\section{Como vinha sendo o desempenho escolar dos alunos das SAPNE?}

Para apreciação do desempenho escolar dos alunos que estavam matriculados nas classes comuns, tomaram-se como indicadores os conceitos finais por eles obtidos nas áreas de ensino Língua Portuguesa, Matemática, Geografia, História, Ciências, Educação Artística e Educação Física, nos anos letivos de 1998 a 2001, e sua freqüência, nesses respectivos anos. 
Não se obteve essas informações para a totalidade dos alunos. Havia uma parcela daqueles alunos que não estavam vinculados à classe comum, ou seja, que só freqüentavam a SAPNE em alguns dias da semana e, por isso, não tinham matrícula no ensino regular. Enfim, por serem alunos que freqüentavam as SAPNE sem qualquer vínculo formal com a rede municipal de ensino não havia informação sobre seu desempenho escolar. Também não foi possível obter tal informação para os alunos matriculados em escola onde não estava situada a SAPNE, pois as professoras não tinham o registro do seu desempenho na classe comum. Ainda, para alguns alunos que freqüentavam a SAPNE da própria escola não foi possível obter os conceitos ou a freqüência, no todo ou em parte, em decorrência da já mencionada diversidade de formas de registros de acompanhamento constatada na coleta de dados.

Com os dados disponíveis - total ou parcialmente -, referentes a 115 alunos, é possível afirmar que a maioria desses tinha obtido conceitos satisfatórios ou plenamente satisfatórios em Educação Artística e Educação Física. Ao que parece, ou os alunos tendem a apresentar habilidades nesses campos ou os professores, ou mesmo a escola, têm como princípio não "reprovar" os alunos nessas atividades.

Nas outras disciplinas, a tendência era a atribuição, aos alunos, do conceito "não satisfatório" no decorrer dos anos escolares, no entanto, não havia uma relação entre o predomínio desses com a decisão de prosseguimento ou não dos estudos nas séries subseqüentes. Os alunos cujos conceitos indicavam uma alteração de "não satisfatório" para "satisfatório", usualmente, eram aqueles que permaneceram na escola e deixaram de freqüentar as SAPNE.

Também não foi possível obter dados para identificar a ocorrência ou não de reprovação escolar para a totalidade dos alunos matriculados em classe comum. Obteve-se essa informação para apenas 148 alunos e verificou-se que as professoras declararam que 34 deles não foram reprovados durante a sua trajetória escolar. Para os demais 114 alunos havia registro de repetência, sendo que dos 114 alunos, 93 tinham uma repetência (30\%) e 21 (7\%) duas repetências, quase todas ocorridas nas $3^{\mathrm{a}}$ e $4^{\mathrm{a}}$ séries $(93,4 \%)$. Entre os repetentes, 76 eram meninos $(66,6 \%)$ e 38 eram meninas $(31,5 \%)$.

Quanto à freqüência às aulas, a maior parte dos alunos tinha registro de um percentual acima de $90 \%$ de presença, embora, como já mencionado, com conceitos "não satisfatórios".

\section{Destaques e discussão dos Resultados}

A pesquisa realizada possibilitou a identificação de características que têm estado presentes nas SAPNE que podem subsidiar ações no sentido de garantir a permanência de alunos que apresentam deficiência mental em uma escola que seja pública, democrática e de qualidade. 
O propósito que direcionou a pesquisa foi o de analisar a SAPNE enquanto estratégia de política educacional, portanto o foco privilegiado foi o registro de evidências relativas a princípios que norteiam tal opção de atendimento e a estrutura e procedimentos de sua implantação na rede de ensino.

Retomam-se aqui algumas constatações desta investigação, com vistas a apreender o que essas revelam enquanto potencial da SAPNE de contribuir no processo de escolarização de alunos com deficiência mental, de modo integrado ao ensino comum.

Destaca-se, inicialmente, que só foi possível registrar a trajetória escolar de parte dos alunos que se encontrava em SAPNE no ano de 1997 por se contar com a presteza das professoras dessas salas. Para os casos em que a professora deixou a SAPNE nos anos subseqüentes, por diferentes razões, para a quase totalidade dos casos também se foi a história dos alunos bem como outros registros do trabalho por ela realizado.

Isso evidencia não haver uma sistemática de acompanhamento do atendimento que se dá em SAPNE, ou mesmo uma orientação comum às escolas para registro e arquivo da documentação relativa à trajetória dos alunos atendidos. Tem ficado a cargo das escolas ou somente da professora dessa sala qualquer iniciativa de organização de informações e fluxo escolar dos que a freqüentam ou de seus egressos. Isso resulta em uma diversidade de dados disponíveis, que variam não só na forma de registro, mas também no seu conteúdo.

Quando se observou o motivo de encaminhamento daqueles alunos de 1997 à SAPNE, pôde-se constatar que muitas das professoras não tinham essa informação registrada. Assim, suas declarações baseavam-se mais em suposições do que em documentação. Para elucidar esse fato, registra-se que apesar de 107 alunos terem sido classificados como deficientes mentais, segundo afirmações das professoras, apenas 67 desses possuíam laudo psicológico e quatro, laudo médico.

No que se refere à trajetória escolar, $26 \%$ dos alunos, sobre os quais foram obtidas informações, não permaneceram no ensino regular, ou seja, por um motivo ou por outro, foi interrompida sua escolarização. Alguns desses alunos foram encaminhados para outros tipos de serviços especializados, o que pode indicar a necessidade de oferta de recursos especiais de educação no âmbito da rede municipal de ensino, para além do atendimento em salas de recursos. Há outros alunos, porém, que sequer estavam tendo algum tipo de atendimento educacional, o que sugere certa negligência do poder público perante a sua responsabilidade em garantir aos mesmos o direito à educação.

Nota-se, portanto, que a SAPNE nem sempre era um recurso suficiente para viabilizar o atendimento integrado de parcela de alunos com deficiência mental na classe comum.

Nas informações a respeito do motivo de saída dos alunos da SAPNE, no decorrer do período 1997/2001, o desejável era que isso ocorresse quando o 
aluno tivesse adquirido autonomia suficiente para dar continuidade aos estudos na classe comum, sem a necessidade de atendimento paralelo. Entretanto, segundo indicaram as professoras, apenas $12 \%$ saíram da SAPNE "por bom desempenho". Em contrapartida, a maior parte das justificativas para o desligamento dos alunos recaiu sobre razões administrativas ou legais e não educacionais. Ainda, em parte das justificativas, as professoras apontaram as mães como responsáveis pela interrupção do atendimento de seus filhos na SAPNE.

Quanto ao desempenho escolar, os dados obtidos permitiram afirmar a predominância de atribuição do conceito "não satisfatório" aos alunos de SAPNE, pelos professores do ensino comum, à exceção das disciplinas de Educação Artística e Física. Essa constatação é indicativa de que apesar de estarem dando continuidade à sua trajetória escolar, muitas vezes os alunos acumulavam conceitos "não satisfatório", o que sugere que seu aprendizado não tinha efetivamente acontecido, ao menos dentro dos padrões estabelecidos pela escola.

Se, por um lado, reconhece-se o valor do princípio da integração, enquanto orientador da oferta de recursos educacionais, como condição mesma de garantia do direito à educação, por outro, entende-se que a educação especial não pode se dar sem o devido planejamento e condições técnicas e materiais, pois, quando isso ocorre, muitos alunos ficam, em realidade, sem atendimento educacional.

Sem dúvida, o que está em questão é o processo de transformação da escola regular, que certamente é lento e complexo, pois supõe confronto com valores há muito arraigados na organização do trabalho escolar. A ruptura com a lógica classificatória e seletiva, dominante nas práticas pedagógicas, é condição para a concretização do direito de todos à educação. A universalização do acesso à educação básica e a viabilização de uma trajetória escolar que possibilite o desenvolvimento de todos os alunos supõe uma escola capaz de acolher as diferenças, o que implica em ressignificação de concepções e práticas usualmente dominantes na escola e nos sistemas de ensino.

Os resultados desta pesquisa permitiram ilustrar que a organização de políticas públicas de acesso e qualidade do processo educacional avança com a perspectiva da educação inclusiva, contudo, tanto no plano teórico como no das políticas e práticas educacionais ainda se evidenciam vicissitudes e controvérsias, talvez, como expressão de indefinições presentes no próprio campo da educação especial. Como manifesta Skliar:

A educação especial, como disciplina formal, em seu discurso e suas práticas hegemônicas, é descontínua em seus paradigmas teóricos; anacrônica em seus princípios e finalidades; relacionada mais com a caridade, a beneficência e a medicalização que com a pedagogia; determinada por técnicas discriminatórias e segregacionistas; distanciada do debate educacional geral e produtora/ reprodutora, também ela, de uma falsa oposição entre inclusão e exclusão. (SKLIAR, 1999, p. 17) 
As indicações trazidas com o estudo acerca da trajetória escolar de alunos com deficiência mental na rede municipal de ensino de São Paulo apontaram para a necessidade de acompanhamento e avaliação das políticas educacionais no sentido de apreciar suas conseqüências e impactos para esse alunado. Também, trouxeram elementos que podem subsidiar redirecionamentos em sua condução, contribuindo para a explicitação da noção de excepcionalidade que, de modo dominante se faz presente no contexto estudado, ao evidenciar suas conseqüências educacionais e sociais. Na expressão de Keogh, excepcionalidade é um constructo relativo porque se define:

[...] em função das visões de normalidade que prevalecem numa determinada cultura e das idéias dominantes sobre o tipo de ação necessária em relação a quem se desvia da norma. O que constitui normalidade varia, naturalmente, de acordo com condições culturais, históricas e econômicas (KEOGH, 1975, p.2).

A avaliação das políticas que se apresentam como potencialmente inclusivas, torna-se iniciativa imperiosa, considerando particularmente a significativa ampliação de matrículas de alunos com necessidades educacionais especiais nas classes comuns da rede regular de ensino, que se constata no Brasil nos anos recentes, como registra a Secretaria de Educação Especial (SEESP), ao divulgar o "Programa de Educação Inclusiva: direito à diversidade":

\begin{abstract}
O programa, por meio de suas ações, tem proporcionado crescente atendimento aos alunos com necessidades educacionais especiais nas escolas e classes comuns da rede regular de ensino. O impacto desta política está expresso nos dados do MEC/INEP, que mostram um crescimento de 76,4\% da matrícula de alunos com necessidades educacionais especiais em classes comuns, passando de 110.704 alunos $(24,6 \%)$ em 2002 para 195.370 alunos $(34,4 \%)$ em 2004 . Os dados do Censo Escolar de 2004 apontam para um total de 566.753 alunos com matrícula na educação especial, sendo que 323.258 estão matriculados na rede pública, representando $57 \%$ das matrículas. (www.mec.gov.br/seesp)
\end{abstract}

Para que se concretize a educação como direito humano e social, sem discriminação, além de um controle quanto à ampliação de acesso à escola se faz urgente um acompanhamento da trajetória desses alunos, ou seja, sua permanência e aprendizagem. Tal perspectiva demanda a intensificação de estudos que se voltem para a identificação e análise de evidências acerca dos resultados e impactos das políticas de educação inclusivas.

Essa compreensão é que motivou o desenvolvimento da pesquisa aqui relatada, cujos resultados, espera-se, venham a colaborar para o polêmico debate sobre inclusão/exclusão escolar de alunos que apresentam deficiência mental e para o delineamento da política educacional do município de São Paulo e de outros municípios e/ou demais esferas públicas. 


\section{REFERÊNCIAS}

BRASIL, Congresso Nacional. (1988). Constituição da República Federativa do Brasil. Brasília: Diário Oficial da União, 05 de outubro.

. Ministério da Justiça. (1997). Declaração de Salamanca e Linha de ação sobre necessidades educativas especiais. Brasília: CORDE.

. Secretaria de Educação Especial. (1995). O processo de integração escolar dos alunos portadores de necessidades educativas especiais no sistema educacional brasileiro. Brasília: MEC/ SEESP, Série Diretrizes; 7.

KEOGH, B.K. (1975). Social and ethical assumptions about special education. In: WEDELL, K. Orientations in special education. London: J Willey e\& Sons.

PRIETO, Rosângela Gavioli. (2000). Política educacional do município de São Paulo: estudo sobre o atendimento de alunos com necessidades educativas especiais, no período de 1986 a 1996. Tese Doutorado. São Paulo: Faculdade de Educação da Universidade de São Paulo.

SÃO PAULO, Secretaria Municipal de Educação. (1993). Decreto nº. 33.981. Diário Oficial do município de São Paulo, 16 de dezembro.

SKLIAR, Carlos. (1999). A invenção e a exclusão da alteridade "deficiente" a partir dos significados da normalidade. In: Educação e Realidade. Porto Alegre, v.24, n.2, jul./dez.. p. $15-32$.

SOUZA, Sandra Maria Zákia Lian e PRIETO, Rosângela Gavioli. (2000). Política de atendimento aos alunos das SAPNE direcionadas ao portador de deficiência mental. Faculdade de Educação da Universidade de São Paulo: Relatório de pesquisa (Mimeo).

(2000). Atendimento educacional aos portadores de deficiência mental na rede municipal de São Paulo: caracterização e análise das SAPNEs. Revista Brasileira de Educação Especial. Marília/SP: UNESP Publicações, v. 7, n. ${ }^{\circ} 1$. p. 101-14.

UNICEF. (1991). Declaração mundial sobre educação para todos e plano de ação para satisfazer as necessidades básicas de aprendizagem. Tradução: Maria de Lourdes Menezes e outros. Brasília: CORDE.

www.mec.gov.br/seesp.

Recebido em 27/07/2006

Aprovado em 30/08/2006 